\title{
Um passeio pelos Estudos de Gênero e a produção do conhecimento
}

\author{
Estudos in(ter)disciplinados: \\ gênero, feminismo, sexualidade. \\ GROSSI, Miriam; LAGO, Mara; \\ NUERNBERG, Adriano (Org.).
}

Florianópolis: Editora Mulheres, 2010. $432 \mathrm{p}$.

O livro Estudos in(ter)disciplinados: gênero, feminismo, sexualidade é uma coletânea comemorativa dos 15 anos do Programa de PósGraduação Interdisciplinar em Ciências Humanas (PPGICH) da UFSC e dos dez anos da área de concentração Estudos de Gênero. Os artigos que o compõem originaram-se das 15 primeiras teses defendidas, entre 2003 e 2009, nesta área de concentração do PPGICH e foram escritos pelos/ as recém-doutores/as com seus/suas orientadores/as.

O livro traz indicadores da produção brasileira de Gênero da última década, apontando caminhos percorridos nas pesquisas da área e lacunas a serem preenchidas. A organização da obra - que parte de aspectos mais conceituais e epistemológicos para os mais cotidianos - contribui para a compreensão do leitor leigo e para o aprofundamento dos já iniciados.

É uma leitura recomendada para distintas disciplinas, e as discussões propostas permitem vislumbrar a aplicabilidade do conceito de Gênero em diversas áreas do saber e por meio de diferentes estratégias de pesquisa. Apesar de não ser o foco primordial da obra, as contr- 
ibuições metodológicas e reflexões éticas suscitadas merecem destaque.

O livro referenda o Feminismo como dimensão indispensável às Ciências Sociais, onde o diálogo entre militância e produção acadêmica faz parte da atuação profissional, e pessoal, deixando patente a ciência como socialmente situada. As ideias discutidas perpassam a desnaturalização e desessencialização de mulher, homem, casamento e amor, trazendo à tona formas de subjetivação como princípios organizadores da sociedade moderna.

A obra divide-se em quatro partes: 1) Teorias e movimentos feministas; 2) Representações de gênero nos campos de saúde e mídia; 3 ) Sexualidades em interfaces com a noção de territorialidade; e 4) Amor e conjugalidades. Alguns artigos assumem características reflexivas e outros se dedicam à revisão bibliográfica ou trazem mais detalhes sobre a metodologia utilizada, seja ela entrevista, etnografia ou pesquisa documental. Com isso, visualizam-se quais filiações teóricas retroalimentam os Estudos de Gênero e reconhecem-se instituições, grupos e associações que fomentam o campo. O livro também apresenta ideias divergentes nos Estudos de Gênero, demonstrando a diversidade do campo sem comprometer o valor da obra. Ao contrário, ela a valoriza, evidenciando a pluralidade de pensamentos, como haveria de ser num campo que se propõe a produzir saberes localizados.

Estudos in(ter)disciplinados denuncia a produção de normatizações e a conservação de padrões de normalidade no que tange a gênero e sexualidade, e ciência e academia. Há uma crítica a algumas formas de produção do conhecimento e às práticas que ele sustenta, delatando a geração e perpetuação do engessamento dos saberes. Problematizam-se os conceitos de normal e patológico, que estabelecem regras sociais e os parâmetros de normalidade e exclusão.

Vale destacar as ideias de Michel Foucault em muitos dos artigos como base para as problematizações citadas. Referências a Félix Guatari, Sandra Harding, Donna Haraway, Georges Canguilhem, Pierre Bourdieu, Judith Butler, Rita Felskic etc. também dão o tom da relação entre gênero, processos de subjetivação e produção científica, expressando o quão complexo e fascinante é este campo, reafirmando que o Feminismo não é um, mas sim Feminismos.

No primeiro capítulo, há um forte teor histórico, esclarecedor dos diálogos possíveis entre Feminismo e Sociologia. Ressalta-se uma nova forma de olhar o humano: menos absoluto, mais relacional e contextual, trazendo à baila a possibilidade de mudanças, especialmente na construção do conhecimento. Destaca-se a relevância desse capítulo para a Antropologia ao salientar o estudo da alteridade e lançar questões sobre o que ou quem seria os Outros, considerados como impulsionadores de diferentes leituras e transformações. Para falar em diversidade, o artigo traz contribuições das teorias queer e pós-coloniais, responsáveis por avanços na análise de processos normalizadores que engendram hegemonia e subalternidade.

O capítulo seguinte traz uma localização histórica mais situada no campo da Psicologia. Refere valiosas informações sobre a Psicologia Social e suas relações com os Estudos de Gênero, citando as revistas de Psicologia que foram/ são importantes para o campo e associações, com destaque para a ABRAPSO - Associação Brasileira de Psicologia Social.

O terceiro artigo desenvolve uma discussão nova e instigante: gênero relacionado às ciências da saúde, naturais e biológicas, demonstrando que a ampliação do conceito é um desafio necessário, especialmente em se tratando de uma proposta de transformação social global. Tendo em vista a produção do conhecimento por grupos pouco reconhecidos, tais como mulheres, estudiosos de países do Hemisfério Sul, negros etc., o artigo salienta o imperativo de posicionar-se na construção de saberes, sempre localizados. Quando as autoras defendem que - olhar das mulheres durante os experimentos pode contemplar pontos não contemplados por homens, pode-se questionar se isso não estaria reforçando ideias de diferenças essencializadas e/ou naturalizadas, constituindo-se num retrocesso em relação às teorias feministas, ou pode-se pensar na tentativa e defesa da representação, pautada no fim da marginalização.

O quarto capítulo defende o feminismo no plural e gênero como um campo e não como uma categoria. Através de uma pesquisa etnográfica com ênfase nas narrativas, identifica a diversidade e a vinculação com Organizações Não-Governamentais como particularidades do feminismo brasileiro, trazendo à tona, inclusive, aspectos financeiros. Tendo em vista os feminismos em diferentes contextos, as autoras salientam as relações entre poder e saber e retomam a discussão entre produção acadêmica e militância, teoria e prática. A partir da pergunta: há uma ciência feminista?, as autoras propõem um fazer científico engajado, que tem como um dos pilares a noção pós-estruturalista de descons- 
trução, em oposição à ciência moderna e seus binarismos.

$\mathrm{O}$ artigo seguinte tem como foco a reprodução assistida. Além de detalhes sobre as dificuldades e possibilidades do campo, as autoras trazem reflexões sobre a transformação da mulher e do homem em unidade a partir da categoria "casal infértil", bem como problematizações sobre as noções de natureza, gênero, sexo etc. Há um item dedicado à paternidade, perfazendo um dos poucos momentos em que um tema ligado a masculinidades é tratado no livro.

O capítulo consecutivo traz uma interface entre mídia, gênero e infância, temas raros de serem abordados juntos. Com base nos Estudos de Gênero, há a problematização da categoria "infância", com ênfase para as dimensões cultural e relacional. Ressalta-se o papel da mídia para as matrizes da identidade feminina infantil, pautada em dicotomias, como masculinos e femininos e adultos e crianças. Haveria uma redefinição a partir da imagem superpoderosa, que reconfigura $\circ$ feminino sem anular as representações anteriormente existentes. Com tensões e reformulações, essas representações convivem, estabelecendo a passividade como estratégia de sedução/erotismo e o estilo de vida infantil feminino ligado ao consumo e à lucratividade. A agência da mulher seria ao mesmo tempo aprisionadora e libertária.

O sétimo artigo fala sobre gênero e sofrimento psíquico à luz de uma visão política. Nele, gênero é visto como campo discursivo e histórico de relações de poder, onde se dá a conformação de subjetividades e as perspectivas de vida. Tendo em vista gênero como ato performático, fala-se em práticas concretas e não em essências naturalizadas, onde se pode explorar a noção de processo e construção singular, quase nunca coerente e consistente. O artigo traz uma belíssima articulação entre conceitos de gênero e subjetividade, atravessada pela discussão sobre cidadania e direitos civis.

A partir de um Serviço de Residência Terapêutica (SRT) e de ideias da Reforma Psiquiátrica, as autoras afirmam a casa como possibilidade de conquista da cidadania e concretização de projetos de vida, e a obediência a padrões como estratégia de inclusão social e reconhecimento da sanidade para as residentes. Trata-se de uma micropolíitica do cotidiano que garante autonomia e emancipação por meio da adoção de uma performance exemplar. Gênero aparece como dispositivo biopolítico de poder, ilustrado pelo controle social exercido pela SRT e como marco norteador para o estabelecimento de parâmetros de saúde. Nota-se a necessidade de construção de uma política de governo que articule gênero e saúde mental, através da comunicação de diversas áreas do conhecimento.

O oitavo capítulo discute as prescrições de gênero em anúncios publicitários. A revista enfocada é considerada colaboradora na constituição de subjetividades através da definição de como deveriam ser as mulheres. Comparando anúncios das décadas de 1950 e 1960, constataram-se permanências e rupturas nas relações de gênero: a convivência entre novo e moderno, a diversidade de valores, hábitos e costumes, e as transformações culturais de uma época. A publicidade é classificada como importante fonte de informação sobre a história da mulher, das memórias privadas. Através da polissemia de imagens e textos, verifica-se que mudanças acontecem de maneira lenta e gradual, num cenário onde se vê a mulher em movimento.

O primeiro artigo da terceira parte traz uma pesquisa documental sobre os relatórios de sexualidade do século XX para demonstrar a condição de emergência histórica e de permanência destes como fontes válidas sobre sexualidade de homens e mulheres. Nele destacam-se a denúncia do papel da ciência como estratégia de poder-saber-prazer e a criação da lógica de normalidade-anormalidade e saúde-doença, através da colocação do sexo em discurso, da produção de verdades e de recursos estatísticos. Os autores ironizam, então, sobre as sexualidades estatisticamente normalizadas, anunciando que o ponto nodal é a norma-verdade, isto é, a sexualidade descritiva convertendo-se em prescritiva.

O artigo subsequente aborda a circulação e configuração do desejo homossexual por meio de uma cartografia de sociabilidades homossexuais. Através de formas diversas de apreensão dos espaços, verificada a partir de uma revisão histórica do circuito gay de Florianópolis, os autores destacam a diversificação das homossexualidades.

Já o capítulo 11 aborda a invisibilidade do homoerotismo feminino, passando pela descoberta da orientação homoerótica e pela vivência das relações afetivas, desembocando em reflexões sobre mudanças neste universo considerado marginal. As autoras remontam ao feminismo de segunda ordem e ao movimento lésbico para questionar a naturalização da heterossexualidade, tida como categoria cultural útil à organização social, hierarquizações, generalizações e exclusões. Em uma esclarecedora articulação entre gênero e sexualidade, as autoras denun- 
ciam que não há lugar para as lésbicas nas políticas de cidadania, na sociedade civil e nas esferas privadas, apontando para as diferenças entre a subordinação deste segmento e a de gênero e raça e reivindicando o homoerotismo feminino como direito humano.

O último artigo da terceira parte é dedicado à vivência do prazer em sexualidades consideradas tipicamente femininas. Numa tentativa de afastar ideias sobre conduta natural e desviante, há uma ênfase na sexualidade como comportamento humano construído culturalmente, expressão de relações sociais e físicas que exigem aprendizado. Constatando que não há grandes mudanças nas relações de gênero no que concerne à sexualidade, o artigo aponta para a insatisfação sexual feminina e a necessidade de maior preparo dos profissionais da saúde para lidar com o tema.

O capítulo 13 denuncia as contradições entre Estado laico e posições religiosas existentes nos discursos de parlamentares e sociedade civil sobre reconhecimento social e jurídico de uniões homossexuais. São postas em xeque noções de família, conjugalidade, sexualidade, paternidade, maternidade, e reafirmada a necessidade de garantia legal para os diversos relacionamentos.

O penúltimo artigo aborda o amor como sentimento e prática social, entendido como ato de conceder a si mesmo ao outro. Há uma compreensão da relação amorosa como híbrida, construída através de práticas sociais, mas vivenciada como sentimento e instituída por roteirizações.

O último artigo trata da construção de conjugalidades homoeróticas numa articulação com identidade gay e ressignificação dos amores masculinos. Os autores mostram que os gays não escapam do modelo conjugal construído pela heteronormatividade, mas que assumir-se gay é um campo de possibilidades para os processos de individualização a partir da revisão das noções de amor, paixão, sexo, prazer, estilo de vida, felicidade e plenitude. O artigo aponta ainda a necessidade de problematizar a noção de possibilidade de escolha, considerada muito naturalizada ultimamente.

Apesar de não enfocar diretamente a violência contra as mulheres - um dos principais temas para os Estudos de Gênero - a coletânea é uma excelente leitura para quem quer se situar no campo, aprofundar seus estudos e questionar a ordem estabelecida. A provocação existente no título do livro traz um importante direcionamento: o parêntese que coloca o termo "ter" em suspenso dá origem à palavra "indisciplinados". Seria uma maneira de apontar para o questionamento que estes estudos fazem em relação à disciplinaridade dos corpos? Se sim, o fez com sucesso.

Laís Oliveira Rodrigues Universidade Federal de Pernambuco Russell Parry Scott Universidade Federal de Pernambuco 